\title{
Financial support for xenotransplantation research
}

\author{
David K.C. Cooper \\ University of Alabama at Birmingham, Birmingham, AL. USA
}

I was asked recently how much financial support had been given to xenotransplantation research worldwide since approximately 2000.

Before that date, there had been very considerable funding from such pharmaceutical companies as (i) Sandoz/Novartis, initially through its acquisition of the biotech company, Imutran, in Cambridge in the UK) and subsequently through support of BioTransplant and Immerge (both in Boston, USA), and (ii) Baxter (through the US biotechnology company, Nextran). These combined pharma companies must have spent several hundred million US dollars in acquiring and supporting these biotech companies during this early optimistic and enthusiastic period. Considerable funds were allocated to developing biosecure pig facilities somewhat prematurely. After 'big pharma' withdrew from the field, support worldwide has come mainly from government sources, though with some significant corporate support in some countries.

As I could not answer the question I had been asked, I contacted several colleagues wellknown in the field of xenotransplantation research (see acknowledgement below) and requested them to provide me with approximate estimates of expenditure on xenotransplantation in their own countries. For the historical record, I summarize this information here (Table 1). It should be emphasized that some estimates, e.g., corporate support in the USA, and local government and corporate support in China, are informed 'guesstimates' rather than true estimates.

It is noteworthy that countries not appearing in the list (because of no or negligible financial support for xenotransplantation research during this century) include the UK (that was very active in the field during the last few years of the $20^{\text {th }}$ century), France, and Canada.

In future years, those interested in the history of medicine will be able to consider whether the financial support that xenotransplantation research has received was well-spent and worthwhile.

To put these data into perspective, as far as I can ascertain, each year the American Diabetes Association (ADA) provides approximately $\$ 37$ million for actual research, the Juvenile Diabetes Research Foundation (JDRF) \$80 million worldwide, the American Cancer Society \$160 million, and the American Heart Association (AHA) \$180 million.

Address for correspondence: David K.C. Cooper MD, PhD, Xenotransplantation Program, University of Alabama at Birmingham (UAB), LHRB 752, $17202^{\text {nd }}$ Avenue South, Birmingham, AL 35294-0007, USA, Tel: 205-996-7772; Fax: 205-934-8344, dkcooper@uabmc.edu. 


\section{Acknowledgments}

I thank the following colleagues for providing data and/or estimates - Michael Breimer, Leo Buhler, Peter Cowan, Emanuele Cozzi, Yifan Dai, Robert Elliott, Pierre Gianello, Bernhard Hering, Takaaki Kobayashi, Shinichi Matsumoto, Shuji Miyagawa, Chung-Gyu Park, Richard Pierson, Bruno Reichart, David Sachs, Hendrik Schuurman, Jean-Paul Soulillou 
Table 1:

Estimate of funding for research into xenotransplantation worldwide since approximately 2000 (in US\$, at today's exchange rates, unless otherwise stated)

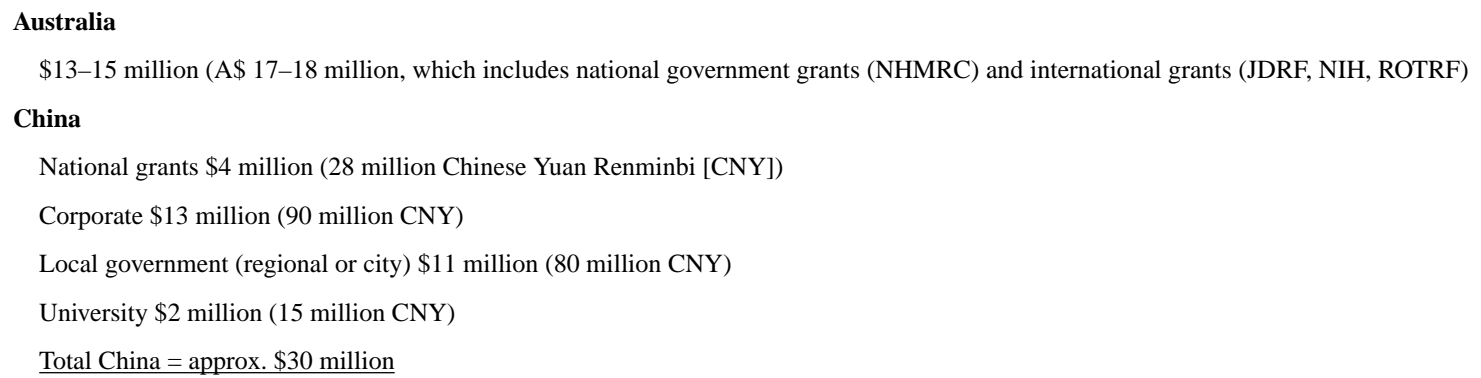

Regional, city, university, hospital, and corporate support probably provided several more million US\$ than included above. It should be remembered that, as research expenses are much lower in China, $\$ 1$ million funds much more research in China than in the USA or Europe.

\section{European Union}

$\$ 39$ million ( $€ 34$ million) consisting of funding for Xenome ( $€ 9.9$ million), Translink ( $€ 6$ million), Xenoislet ( $€ 6$ million), BIOSID ( $€ 3.5$ million, delivery of islets), BIOCAPAN ( $€ 3.5$ million, encapsulation of islets), INANOBIT ( $€ 3.5$ million, imaging of islets), and Xenotransplantation ( $€ 1.5$ million, strategies for the prevention of carbohydrate related [hyperacute] rejection) (1997-2000).

Additional support from countries within the $E U$

Belgium \$2.2 million ( $€ 1.9$ million), consisting of national government support of $€ 0.9$ million, and regional government support of $€ 1.0$ million.

Germany \$31 million ( $€ 27$ million), from the German Research Foundation and the Bavarian Research Foundation, almost entirely awarded to the DFG SFB Transregio.

Italy \$3.3 million ( $€ 2.8$ million), consisting of national government support of $€ 0.6$ million, and regional government support of $€ 2.2$ million)

Sweden $\$ 12$ ( $€ 14$ million), consisting of national and regional governmental grants as well as private funds.

Total EU $=$ approx. $\$ 88$ million

\section{Japan}

\$13 million (1,300 million yen)

\section{New Zealand}

\$46 million (NZ\$70 million) consisting of government grants of NZ\$3 million, JDRF grant of US\$3.5 million, and corporate investment of NZ\$64 million (all funding for Diatranz Ltd, Living Cell Therapeutics, or Diatranz Otsuka Ltd).

\section{South Korea}

$\$ 50$ million (55,000 million won) of government funding.

\section{Switzerland}

\$7.16 million (7.46 million CHF) from the Swiss National Research Foundation

USA

National Institutes of Health (NIH) $\$ 60$ million (approximately $\$ 4$ million/year for the past 15 years)

Charitable funding sources (e.g., JDRF, ADA, Schulze Foundation) \$30 million

Corporate $\$ 100$ million

Total USA = approx. $\$ 190$ million

\section{ESTIMATED WORLDWIDE APPROXIMATE TOTAL $=\$ 438$ million}

